\begin{tabular}{ll|l}
\cline { 2 - 3 } & \multicolumn{2}{l}{ Intervent Neurol 2013;2:132-143 } \\
\cline { 2 - 3 } & $\begin{array}{l}\text { DOI: 10.1159/000357503 2014 S. Karger AG, Basel } \\
\text { Published online: March 25, 2014 }\end{array}$ & $\begin{array}{l}\text { 1664-9737/14/0023-0132\$39.50/0 } \\
\text { www.karger.com/ine }\end{array}$ \\
\hline
\end{tabular}

\title{
Idiopathic Intracranial Hypertension: A Systematic Analysis of Transverse Sinus Stenting
}

\author{
Mohamed S. Teleb ${ }^{a}$ Matthew E. Cziep ${ }^{a}$ Marc A. Lazzaro ${ }^{a-c}$ \\ Ayman Gheith $^{a} \quad$ Kaiz Asif $^{a} \quad$ Bernd Remler $^{a, d}$ Osama O. Zaidat ${ }^{a-c}$ \\ Departments of a Neurology, ${ }^{b}$ Neurosurgery, ${ }^{\mathrm{c}}$ Radiology and ${ }^{\mathrm{d}}$ Ophthalmology, \\ Medical College of Wisconsin/Froedtert Hospital, Milwaukee, Wisc., USA
}

\section{Key Words}

Idiopathic intracranial hypertension - Venous stenosis - Pseudotumor cerebri · Angiography . Stenosis $\cdot$ Stenting $\cdot$ Sinus stenting

\begin{abstract}
Background: Idiopathic intracranial hypertension (IIH) is a disorder characterized by signs and symptoms of increased intracranial pressure without structural cause seen on conventional imaging. Hallmark treatment after failed medical management has been CSF shunting or optic nerve fenestration with the objective of preserving vision. Recently, there have been multiple case reports and case series on dural sinus stenting for this disorder. Objective: We aim to review all published cases and case series of dural sinus stenting for $\mathrm{IIH}$, with analysis of patients' presenting symptoms, objective findings (CSF pressures, papilledema, pressure gradients across dural sinuses), follow-up of objective findings, and complications. Methods: A Medline search was performed to identify studies meeting prespecified criteria of a case report or case series of patients treated with dural sinus stent placement for IIH. The papers were reviewed and data were extracted. Results: A total of 22 studies were identified, of which 19 studies (including a total of 207 patients) met the criteria and were included in the analysis. Only three major complications related to the procedure were identified. Headaches resolved or improved in $81 \%$ of patients. Papilledema improved in $90 \%$ of cases (172 of 189 patients). Sinus pressure decreased from an average of 30.3 to $15 \mathrm{~mm} \mathrm{Hg}$. Sinus pressure gradient decreased from $18.5 \mathrm{~mm} \mathrm{Hg}(\mathrm{n}=185)$ to $3.2 \mathrm{~mm} \mathrm{Hg}(\mathrm{n}=172)$. Stenting had an overall symptom improvement rate of $87 \%$. Conclusion: Although all published case reports and case series
\end{abstract}

M.E.C. is the co-first author. 
are nonrandomized, the low complication and high symptom improvement rate make dural sinus stenting for IIH a potential alternative surgical treatment. Standardized patient selection and randomization trials or registry are warranted.

(C) 2014 S. Karger AG, Basel

\section{Introduction}

Idiopathic intracranial hypertension $(\mathrm{IIH})$ is a syndrome of increased intracranial pressure (ICP) of unknown etiology. Patients present with symptoms of increased ICP including headache, tinnitus, papilledema, visual defects, nausea, and cranial nerve palsies (most commonly cranial nerve 6, although others have been reported). If not recognized early and treated, IIH can lead to blindness. The hallmark features of this disease are symptoms of increased ICP without conventional and radiological abnormalities [1, 2]. Many mechanisms have been proposed, including parenchymal edema, increased cerebral blood volume, venous outflow obstruction, and obesity-related increased central venous pressure, but no consensus on the pathophysiological causes exists [3]. Venous stent placement as a treatment option for IIH is a relatively new treatment modality introduced a decade ago. Retrospective, nonrandomized literature has demonstrated symptom improvement [4-10]. In a recent review, not all issues have been addressed [11]; therefore, with this study, we wanted to add a more comprehensive review to the literature. We aimed to investigate all case reports and case series that had been published on this treatment technique for IIH with the intention of looking at patients' presenting symptoms, complications from procedures, recurrence, technical aspects, and outcomes.

\section{Methods}

A Medline search was performed using different combinations of the following terms: 'pseudotumor cerebri venous stent placement' and 'idiopathic intracranial hypertension venous stent'. A similar search was run in Google Scholar and PubMed. Our search was limited to the English language and articles with an English translation. Only those reports designed as a case report or case series of patients treated with dural sinus stent placement for IIH were included. Review papers were excluded. Our search was limited to the last 15 years (1998 to May 2013). Studies with likely consecutive inclusion of the same patient(s), inadequate or irrelevant data were excluded. We also included a total of 22 patients from our institution.

The papers were reviewed and data were extracted. An Excel spreadsheet with objective values was created. Basic statistical methods for mean, maximum and minimum values as well as paired Student's t tests were conducted to evaluate the data sets before and after treatment when applicable. Where data were not available in all studies, the smaller subgroups were analyzed. The following website was used for the t test calculations: http://graphpad. com/quickcalcs/ttest2/.

\section{Results}

A total of 22 studies were identified, of which 19 met the prespecified criteria [4-10, 12-23]. A total of 207 affected individuals were treated for IIH with venous sinus stent placement. All individuals expressed some symptoms of $\mathrm{IIH}$, the most prominent being 


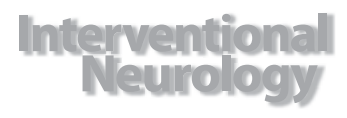

\begin{tabular}{l|l}
\hline Intervent Neurol 2013;2:132-143 \\
\hline DOI: $10.1159 / 000357503$ & $\begin{array}{l}\text { ○ 2014 S. Karger AG, Basel } \\
\text { www.karger.com/ine }\end{array}$ \\
\hline Teleb et al.: Idiopathic Intracranial Hypertension: A Systematic Analysis of Transverse
\end{tabular}

Teleb et al.: Idiopathic Intracranial Hypertension: A Systematic Analysis of Transverse
Sinus Stenting

Table 1. Overview of dural sinus stenting cases: major reported symptoms and their outcomes

\begin{tabular}{|c|c|c|c|c|c|c|c|c|c|c|c|}
\hline \multirow[t]{2}{*}{ First author } & \multirow{2}{*}{$\begin{array}{l}\text { Cases, } \\
\mathrm{f} / \mathrm{m}\end{array}$} & \multicolumn{3}{|l|}{ Headache } & \multicolumn{3}{|c|}{ Papilledema } & \multicolumn{3}{|c|}{ Visual problems } & \multirow{2}{*}{$\begin{array}{l}\text { Follow-up } \\
\text { (mean), } \\
\text { months }\end{array}$} \\
\hline & & $\begin{array}{l}\text { resolved/ } \\
\text { improved }\end{array}$ & $\begin{array}{l}\text { no } \\
\Delta\end{array}$ & worse & $\begin{array}{l}\text { resolved/ } \\
\text { improved }\end{array}$ & $\begin{array}{l}\text { no } \\
\Delta\end{array}$ & worse & $\begin{array}{l}\text { resolved/ } \\
\text { improved }\end{array}$ & $\begin{array}{l}\text { no } \\
\Delta\end{array}$ & worse & \\
\hline Ahmed [12], 2011 & $47 / 5$ & 40 & 3 & 0 & 46 & 0 & 0 & 32 & 11 & 0 & $2-108(24)$ \\
\hline Albuquerque [13], 2011 & $15 / 3$ & 16 & 1 & 1 & & & & & & & $2-40(20)$ \\
\hline Arac [20], 2009 & $1 / 0$ & 1 & 0 & 0 & 0 & 1 & 0 & 0 & 1 & 0 & 2 \\
\hline Bussière [14], 2010 & $10 / 0$ & 10 & 0 & 0 & 9 & 0 & 0 & 4 & 0 & 0 & $3-60$ \\
\hline Donnet [9], 2008 & $8 / 2$ & 8 & 2 & 0 & 10 & 0 & 0 & 6 & 4 & 0 & $6-36$ \\
\hline Fields [6], 2012 & $15 / 0$ & 10 & 4 & 1 & 15 & 0 & 0 & 7 & 2 & 3 & $3-44(9)$ \\
\hline He [10], 2012 & 24 & 16 & 8 & 0 & 10 & 14 & 0 & 13 & 11 & 0 & $2-19$ \\
\hline Higgins [5], 2003 & $12 / 0$ & 7 & 5 & 0 & 5 & 3 & 0 & & & & $2-26$ \\
\hline Higgins [4], 2002 & $1 / 0$ & 1 & 0 & 0 & 1 & 0 & 0 & & & & 12 \\
\hline Khalia [21], 2010 & $18 / 4$ & 18 & 4 & 0 & 16 & 0 & 0 & 13 & 7 & 0 & $3-24$ \\
\hline Kumpe [7], 2012 & $12 / 6$ & 10 & 2 & 0 & 16 & 2 & 0 & 18 & 0 & 0 & $11-136(44)$ \\
\hline Lazzaro [19], 2012 & $3 / 0$ & 2 & 1 & 0 & 3 & 0 & 0 & 3 & 0 & 0 & $1-21(11)$ \\
\hline Ogungbo [15], 2003 & $1 / 0$ & 1 & 0 & 0 & 1 & 0 & 0 & 1 & 0 & 0 & 12 \\
\hline Owler [18], 2003 & $3 / 1$ & 4 & 0 & 0 & 2 & 1 & 0 & 4 & 0 & 0 & $5-12$ \\
\hline Paquet [17], 2008 & $1 / 0$ & 1 & 0 & 0 & 1 & 0 & 0 & 1 & 0 & 0 & \\
\hline Rajpal [16], 2005 & $0 / 1$ & 1 & 0 & 0 & 1 & 0 & 0 & 1 & 0 & 0 & 6 \\
\hline Radvany [8], 2013 & $11 / 1$ & 7 & 5 & 0 & 11 & 1 & 0 & 11 & 0 & 1 & $9-36(16)$ \\
\hline Teleb [23], 2012 & $1 / 0$ & 1 & 0 & 0 & 1 & 0 & 0 & 1 & 0 & 0 & 6 \\
\hline Zheng [22], 2010 & $1 / 0$ & 1 & 0 & 0 & 1 & 0 & 0 & 1 & 0 & 0 & 3 \\
\hline
\end{tabular}

$\Delta=$ Change.

${ }^{a}$ Case series presented in abstract form at the 2010 Annual Meeting of the American Academy of Neurology, Poster P05.284.

headache and papilledema, while fewer had vision obscurations or tinnitus. Table 1 shows the most common symptoms per case series.

\section{Selection}

Unfortunately, selection criteria were not uniform. Not all patients had papilledema or visual disturbances as demonstrated above. The only universal finding was elevated ICP and headache. Most large series only stented patients with a gradient of $\geq 10 \mathrm{~mm} \mathrm{Hg}[5-7,9,14$, $18,19]$, with three exceptions: Ahmed et al. [12] had stenting criteria of $\geq 8 \mathrm{~mm} \mathrm{Hg}$, Radvany et al. [8] used $\geq 4 \mathrm{~mm} \mathrm{Hg}$, and Albuquerque et al. [13] did not report pressure gradients. Fields et al. [6] only stented patients whose dominant sinus had stenosis. All series also included patients who had failed medical or surgical treatment.

\section{Headache}

Of the 207 patients, 192 presented with headaches; the duration of these symptoms ranged from a few weeks to several years. Following treatment, headaches completely resolved in 72 patients, improved in 83, remained the same in 35, and became worse in 2 patients. This equates to an improvement rate of $81 \%$. Long-term durability of headache resolution was not reported (table 1).

\section{Papilledema}

Of the 19 studies, 18 reported on papilledema and included 189 patients. A total of 172 of $189(90 \%)$ patients presented with papilledema. After treatment, the papilledema resolved in 126 patients, improved in 23, and remained unchanged in 22 . The improvement rate after treatment of papilledema was $87 \%$. Unfortunately, the exact time course for resolution or 
improvement is not reported; however, most report that eye exam was done during the first follow-up assessment which was performed after weeks to months later. Radvany et al.'s [8] study specifically stated that eye exams where carried out between 6 and 12 weeks (table 1 ).

\section{Visual Obscurations}

Sixteen studies, including 176 of 207 (85\%) patients, reported on visual obscurations. Of the 176 individuals, 156 were found to have visual disturbances (acuity, field loss, diplopia, etc.). Treatment completely resolved visual disturbances or improved vision in 116 patients and halted deterioration in 36. In 4 patients, vision deteriorated after stent placement. In preventing visual problems from progressively becoming worse, the success rate was $97 \%$, but in improving or resolving visual disturbances, the success rate was $74 \%$ (table 1 ).

\section{Tinnitus}

Only 10 of 19 studies $(n=153)$ reported on patients with tinnitus. Sixty-five patients (42\%) reported suffering from tinnitus. Following stenting, 29 patients reported resolution, 33 stated improvement, and 3 reported no change. Treatment showed a 95\% improvement of tinnitus.

\section{CSF Pressure}

Not all studies reported explicit individual CSF opening pressures before and after endovascular therapy of IIH. For those that did, almost all only reported the preprocedure opening pressure (15 of 19). The mean CSF opening pressure before treatment was $36.3 \mathrm{~cm} \mathrm{H}_{2} \mathrm{O}$ with a range of $25-73 \mathrm{~cm} \mathrm{H}_{2} \mathrm{O}(\mathrm{n}=100)$ [4, 5, 7-9, 15-18, 22, 23]. After stent placement, six studies had a mean CSF opening pressure of $19.2 \mathrm{~cm} \mathrm{H}_{2} \mathrm{O}$ with a range of 9-26 $\mathrm{cm} \mathrm{H}_{2} \mathrm{O}(\mathrm{n}=20)[9,15$, $18,22]$. The mean pressure decreased by $16.3 \mathrm{~cm} \mathrm{H}_{2} \mathrm{O}$ (table 2).

\section{Sinus Pressure}

Sinus pressure before treatment had a mean of $30.3 \mathrm{~mm} \mathrm{Hg} \mathrm{(15-94} \mathrm{mm} \mathrm{Hg}$ ) reported in 14 of 19 studies ( $\mathrm{n}=107)[4,5,9,12,15-18,22,23]$. Only seven studies reported pressure before and after treatment $(\mathrm{n}=111)[12,18,23]$. After stenting, sinus pressures dropped to a mean of $15 \mathrm{~mm} \mathrm{Hg}(6-33 \mathrm{~mm} \mathrm{Hg})$.

\section{Sinus Pressure Gradient}

The mean pressure gradient reported in 18 studies was $18.5 \mathrm{~mm} \mathrm{Hg} \mathrm{(3-50} \mathrm{mm} \mathrm{Hg,} \mathrm{n}=$ 185) $[4-9,12,14,15,17-20,22,23]$. After stenting, the mean gradient dropped to $3.2 \mathrm{~mm} \mathrm{Hg}$ (0-23 mm Hg, $\mathrm{n}=172)$, i.e. a reduction of $15.3 \mathrm{~mm} \mathrm{Hg}$ in 14 studies [4-8, 12, 14, 18-23] (table 2).

\section{Stent Patency}

Over the follow-up period ranging from 2 to 108 months, all stents remained patent. There were two reports of in-stent thrombosis; both were cleared with antithrombotic treatment [5].

\section{Antithrombotic Regimen}

The most commonly reported regimen among the studies covered in this review consists of a dual antiplatelet therapy (aspirin and clopidogrel) for 3-5 days prior to treatment, heparin during treatment, dual antiplatelet therapy for 3-6 months following treatment, followed by aspirin for 1 year or more [6, 7, 12-14]. One study used only a single antiplatelet drug (clopidogrel) [9], and others used warfarin for 8 weeks followed by aspirin for 6 months or more $[4,5,16]$. 
Teleb et al.: Idiopathic Intracranial Hypertension: A Systematic Analysis of Transverse Sinus Stenting

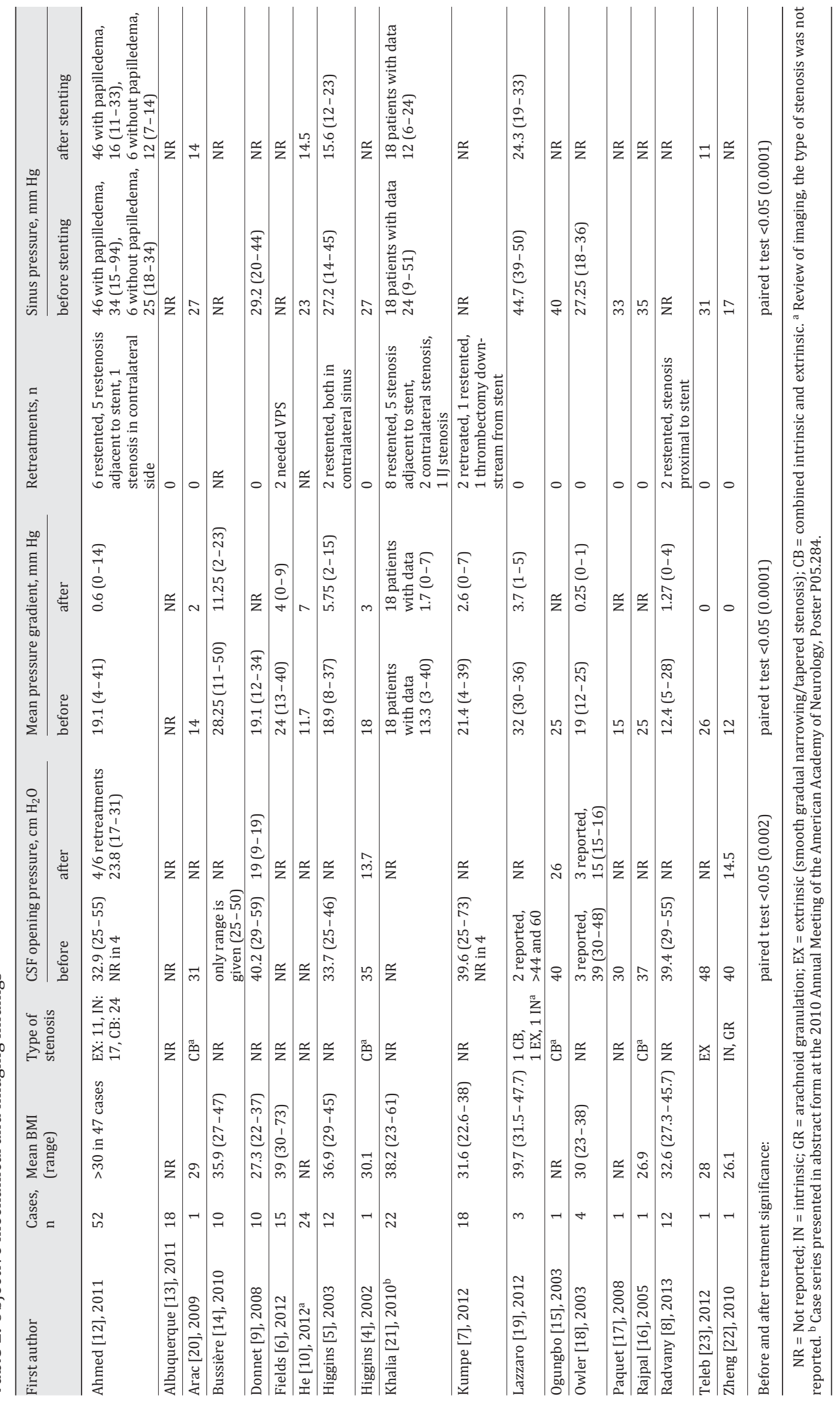




\section{Types of Stenosis}

The described type of venous stenosis associated with IIH is extrinsic, intrinsic or a combination [24]. Ironically, Farb et al. [24] described this before most of the reported case series, yet only few studies comment on this subject although most of them refer to the article of Farb's group. Of all series and reports, only Ahmed et al. [12] and Zheng et al. [22] report on an intrinsic arachnoid granulation. For case series or reports where imaging was available, the authors classified the type of stenosis (table 2).

\section{Technical and Procedural Aspects}

Most procedures reported in case series were performed under general anesthesia. Interestingly, Kumpe et al. [7] reported pressure with and without general anesthesia and noticed that 11 of 13 patients, who had pressures measured with and without anesthesia, had lower pressures under general anesthesia. The median and mean pressures were 21.1 and $21.5 \mathrm{~mm} \mathrm{Hg}$ before and 10 and $13.7 \mathrm{~mm} \mathrm{Hg}$ after the procedure, respectively. Preprocedure antiplatelet regimens were different as discussed above.

Below, the general treatment steps are described; however, every case series differed slightly. Vascular access is achieved using a 6- to 9-French-long sheath placed into the common femoral vein. After achieving access, a heparin bolus is administered followed by continuous infusion to maintain a clotting time of 2.5-3.5 times the baseline value throughout the duration of the procedure $[7,12,13]$. The sheath and a guide catheter are advanced over a wire to the jugular bulb. A microcatheter over a microwire is advanced from the jugular bulb to the superior sagittal sinus, and pressures are measured after withdrawing the microwire and attaching the microcatheter to a manometer, which measures pressure in millimeter of mercury. The microcatheter is withdrawn to the prestenotic transverse sinus segment and eventually to the poststenotic sigmoid sinus, and a pressure gradient is obtained across the stenotic area. This is repeated on the contralateral side by crossing the torcula and advancing the microwire and microcatheter to the contralateral jugular bulb then to the sigmoid sinus and to the transverse sinus. Again, the microwire is withdrawn and pressures are measured at the desired areas.

Once pressures are obtained, the microwire is advanced to the contralateral distal transverse sinus or superior sagittal sinus, and the microcatheter is exchanged for a stent. If tracking of the stent is difficult, a larger buddy wire can be used, the large guide catheter can be advanced past the stenosis to allow tracking of the stent, or the microwire can be exchanged for a stiffer microwire.

Once the stent is deployed and if a stenosis existed, a balloon is tracked to the area of stenosis and balloon angioplasty is performed to expand the stent. When satisfactory stenting is achieved, the microcatheter and microwire are reintroduced and pressures are obtained again to document poststenting pressures. Balloon angioplasty can be performed first, but all steps are similar except when a balloon is used instead of a stent (see fig. 1 for procedure steps).

\section{Complications}

In the 207 treated patients, only three major complications directly related to stent placement occurred: 1 case of vein perforation leading to subdural hematoma [12], 1 case in which a retroperitoneal hematoma developed but did not require treatment [13], and 1 case of transient contrast extravasation [14]. Other indirectly related complications included allergies to drugs administered prior to surgery (aspirin or clopidogrel), allergies to anesthesia, deep venous thrombosis, and mild transient headache lasting for a few weeks possibly due to dural stretching from the placed stent. There was one report of subdural, subarachnoid, and intracerebral bleeding during an emergency treatment for IIH but on the side contralateral to the stent placement [12]. 

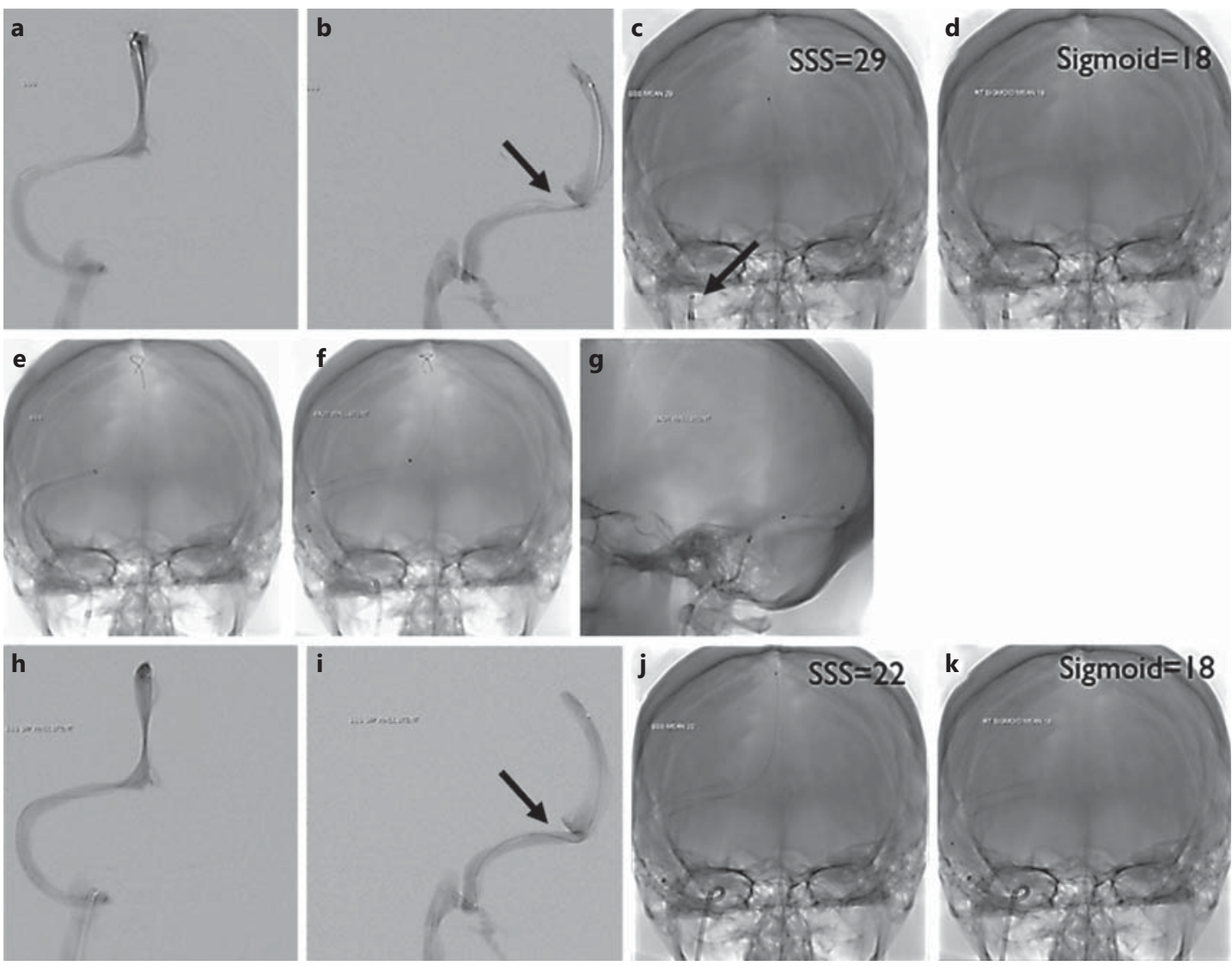

Fig. 1. a, b Venography via microcatheter run from the superior sagittal sinus. c, $\mathbf{d}$ Single shot of the microcatheter. A sample of areas of interest is shown and the mean pressure is labeled. The superior sagittal sinus pressure is $29 \mathrm{~mm} \mathrm{Hg}$ and the sigmoid sinus pressure is $18 \mathrm{~mm} \mathrm{Hg}$, giving a gradient of $11 \mathrm{~mm} \mathrm{Hg}$. Notice the sheath and guide catheter in the jugular bulb. e Single shot with guide catheter taken across the area of stenosis with a stiff microwire in the superior sagittal sinus in AP view. $\mathbf{f}, \mathbf{g}$ Single shot of the stent in AP and lateral projection. $\mathbf{h}$, $\mathbf{i}$ Venography performed again from the superior sagittal sinus microcatheter run poststenting. j, k Single shot of the microcatheter after treatment. A sample of areas of interest is imaged with a mean pressure labeled poststenting. The superior sagittal sinus pressure is $22 \mathrm{~mm} \mathrm{Hg}$ and the sigmoid sinus pressure is $18 \mathrm{~mm} \mathrm{Hg}$, giving a gradient of $4 \mathrm{~mm} \mathrm{Hg}$.

\section{Retreatment}

Retreatment rates ranged from 0 to $33 \%[9,21]$. Six articles report retreatment in atotal of 22 of 207 (10.6\%) patients undergoing further treatment. Kumpe et al. [7] reported that 1 of 18 patients needed retreatment. Fields et al. [6] did not report retreatment, but 2 of 16 patients needed a ventriculoperitoneal shunt and another 2 of 16 underwent bilateral stenting during one session. This gives a rate of 4 of $16(25 \%)$ patients who needed extra treatment. Another large case series had a retreatment rate of $12 \%$ ( 6 of 52 patients) [12]. All 6 patients showed recurrence due to restenosis and improved after retreatment (table 2).

\section{Overall Clinical Outcome}

Of the 207 treated patients, 181 showed improvement or complete resolution of symptoms, 27 reported no change of symptoms, 1 reported worsening of symptoms, and 3 patients were lost to long-term follow-up. The follow-up time span ranged from 2 months 
Teleb et al.: Idiopathic Intracranial Hypertension: A Systematic Analysis of Transverse Sinus Stenting

to 9 years. Most patients who still had symptoms reported having mild headaches that were manageable with medications. Stenting had an overall symptom improvement rate of $87 \%$.

\section{Discussion}

\section{Clinical Reasoning - Symptoms and Results}

From the systematic analysis above, the published case series are in general consistent. Papilledema resolving in most patients is a consistent finding in the case series. Pulsatile tinnitus or other head noise was not reported in most case series, although it is one of the most consistent symptoms in IIH presenting in $60 \%$ of patients [25]. However, when pulsatile tinnitus was addressed, it showed resolution. Lastly, all pressure gradients had a significant change and resolution of pressure gradient to a normal gradient below $5 \mathrm{~mm} \mathrm{Hg}[6,7,12,26]$. Our Student $t$ test was statistically significant for a change in pressure gradient and venous sinus pressure (table 2).

The most frequently reported symptom, although not described in an objective way except in three studies, is resolution of headache $[7,8,27]$. Most case series reportimprovement but not complete resolution in most patients $[5-7,12,13]$. A recently published case series even reported that 10 of 12 female patients still had headaches despite resolution of papilledema [7]. Another, series only reported improvement in headaches, but did not mention the type or degree of symptom resolution [13]. This is in line with the literature that reports the coexistence of IIH with migraines and chronic daily headaches [28-32]. In addition, IIH patients have been reported to have allodynia and to be very sensitive to all types of pain [33]. Therefore, it is imperative to classify the type of headache before and after relief of ICP.

The overall picture is that objective findings tend to resolve but subjective findings, most notably headaches, show improvement but do not resolve. Keeping our results and those of others in mind, we do not recommend endovascular treatment of patients who suffer only from headache, unless it is disabling and improvement would warrant the risks of the procedure.

\section{Pathophysiology and Imaging}

Although our systematic analysis was not about pathophysiology and imaging, we believe that it is important to discuss it, as it may dictate which patients may benefit from this treatment modality. The annual incidence of IIH is between 0.9 and 1.07 per 100,000 inhabitants in the US and 15-19 cases per 100,000 in overweight women between the ages of 20-44 years [34,35]. Cerebral sinus stenosis may be present in $30-93 \%$ of patients with IIH $[2,24,36,37]$. The more worrisome issue concerning imaging is that stenosis can be overlooked as a normal variant due to granulation, artifact, or actually a normal variant. Higgins et al. [36] reanalyzed $20 \mathrm{IIH}$ patients, whose magnetic resonance venograms were initially read as normal, specifically looking for signal dropout and comparing them to 40 controls without headaches. Thirteen of the $20 \mathrm{IIH}$ patients had bilateral transverse sinus flow gaps compared to none of the 40 controls, giving a rate of 65 versus $0 \%$, respectively [38]. Currently, it is well accepted that most IIH patients undergo transverse sinus stenosis [39]. This means that most patients do not need aggressive surgical treatment, and stenoses have probably no influence on the outcome of IIH [39].

Aside from different and subjective interpretive standards, temporary resolution of venous stenosis can occur after CSF drainage [40]. Therefore, we recommend venography with manometry even in cases where imaging was read as normal in severe refractory or fulminant cases. 


\section{Procedure and Complications}

Technical success was achieved in more than $95 \%$ of the patients. The exception was a stent that could not be tracked to the appropriate position in the sinus. There were three major complications related to the procedure giving an acceptable major complication rate of $1.5 \%$. Possible risk associated with endovascular treatment includes the risk of infection, bleeding, venous damage from catheters or wire, venous thrombosis, emboli and subdural hematoma.

In-stent thrombosis associated with venous sinus stenting is low. Over the follow-up period of 2-108 months, there were 2 reported cases of in-stent thrombosis, with a rate of $1.6 \%$. The 2 cases of in-stent thrombosis which were successfully treated occurred in patients receiving treatment of warfarin following the procedure [5].

This rate is similar to other rates of in-stent thrombosis when stenting veins in nonthrombotic patients. Ludyga et al. [41], when stenting for cerebrospinal venous insufficiency as a treatment for multiple sclerosis, reported two incidents of in-stent thrombosis out of 152 cases, with a rate of $1.2 \%$. Ye et al. [42] reported a primary patency rate of $98.7 \%(n=205)$ after 4 years of follow-up when treating nonthrombotic iliac vein compression lesions. The patency rate after treatment of rare thrombotic events was $100 \%$. The most commonly reported regimens among the studies covered in this review consist of dual antiplatelet therapy (aspirin and clopidogrel) for 3-5 days prior to treatment, heparin during treatment, dual antiplatelet therapy for 3-6 months following treatment, followed by aspirin for 1 year or more [6, 7, 12-14]. One study used only a single antiplatelet drug (clopidogrel) [9], and others used warfarin for 8 weeks followed by aspirin for 6 months or more $[4,5,16]$.

Types of Stenoses

Evidence also points to obstruction of venous outflow due to causes other than an elevated ICP. One case series showed evidence of arachnoid granulations or septae possibly causing sinus stenosis [12]. Another case series reported on a case of stenosis caused by an obstruction consistent with fat deposits, and 2 cases of patients with functioning shunts and existent stenoses [18]. In addition, the magnetic resonance venograms studies by Farb et al. [24, 43] report on these different types of stenoses. Unfortunately, few studies report on this subject; however, it could possibly affect the result of the endovascular treatment, as intrinsic stenosis can be the initial cause in a particular patient, which could possibly have a positive influence in this subset of patients.

\section{Retreatment}

The different rates could be due to longer follow-up periods as well as some case series having refractory patients treated with ventriculoperitoneal shunts as opposed to endovascular retreatment. Although the numbers are too small to show significance, a higher pressure gradient, more complete gradient resolution, and unilateral as opposed to bilateral stenosis seemed to favor the need for only one treatment.

\section{Other Treatment and Overall Analysis}

Other invasive treatment for IIH includes optic nerve sheath fenestration and ventriculoperitoneal shunt/lumboperitoneal shunt placement. Shunts have good initial results but their long-term efficacy and high rate of revision is undesirable. Shunts for IIH have an $80 \%$ revision rate at 3 years, with severe headache recurrence in $48 \%$ of patients despite functioning [44]. Optic nerve sheath fenestration has a procedural complication rate ranging from 23 to $40 \%$, which includes blindness [45-48].

Currently, sinus venous stenting for IIH seems safer and as efficacious as ventriculoperitoneal shunting as well as optic nerve fenestration as evidenced by our analysis. However, 
Table 3. Proposed criteria for cerebral venous stenting

Major criteria (all required for qualification)

Failed maximal medical therapy or fulminant course refractory to medical treatment with rapidly worsening vision

Presence of pressure gradient across the stenosis $\geq 8 \mathrm{~mm} \mathrm{Hg}$

Pressure $\geq 22 \mathrm{~mm} \mathrm{Hg}\left(30 \mathrm{~cm} \mathrm{H}_{2} \mathrm{O}\right)$

Visual changes, papilledema, or other focal objective neurological symptoms, headaches only if

severely disabling

No contraindications to dual antiplatelet therapy

Minor criteria (one required for qualification)

Intolerance to repeated lumbar puncture or lumbar drain

Diagnosis of dural sinus stenosis $\geq 50 \%$ on CT or MR venography

Failed surgical shunting procedure or failed optic nerve fenestration

Pulsatility seen on manometry which is attenuated after stenosis

Patient preference

this applies only to the initial procedural risk and short-term follow-up. Larger prospective trials with long-term follow-up are required to effectively quantify the risks and benefits of stenting in refractory IIH patients.

The time frame could skew the results towards a more favorable result as there are fewer individuals with long-term follow-up who could possibly have more complications, than those with shorter follow-up periods. Currently, there is only one phase 1 prospective safety trial (funded by the NIH and published by the Cornell University, New York, N.Y., USA), with the aim of enrolling 20 patients over 24 months [49]. In the future, a multicenter study is needed to fully evaluate the efficacy of venous sinus stenting for IIH.

We have suggested a criterion for patient selection in table 3 . Endovascular management of IIH patients should be considered in patients who have disabling symptoms after maximal medical therapy or fulminant cases with dural sinus stenosis. These are only proposed criteria based on our local experience and published literature which require prospective registries and trials for validation. However, there is still much debate about the use of stenting in IIH, especially in the literature on neuro-ophthalmology, as evidenced by recent point-counterpoint article [27].

\section{Conclusion}

Endovascular management of dural sinus stenosis appears technically feasible and safe. It is clinically efficacious in patients with IIH who failed medical and surgical therapy with dural sinus stenosis. It should be considered after failing maximal medical therapy. Lastly, we suggest creation of a formal multicenter clinical registry to prospectively measure safety and long-term efficacy of the procedure. Our proposed registry name is STRIPE (Stenting To Relieve Intracranial Pressure Endovascularly).

\section{Acknowledgement}

This publication was supported by the National Center for Advancing Translational Sciences, National Institutes of Health, through Grant Number 8UL1TR000055. Its contents are solely the responsibility of the authors and do not necessarily represent the official views of the NIH. 


\begin{tabular}{l|l}
\hline \multicolumn{2}{l}{ Intervent Neurol 2013;2:132-143 } \\
\hline DOI: $\underline{10.1159 / 000357503}$ & $\begin{array}{l}\text { C 2014 S. Karger AG, Basel } \\
\text { www.karger.com/ine }\end{array}$ \\
\hline
\end{tabular}

Teleb et al.: Idiopathic Intracranial Hypertension: A Systematic Analysis of Transverse Sinus Stenting

\section{Disclosure Statement}

The authors have no competing interests. There was no external funding for this review.

\section{References}

1 Ball AK, Clarke CE: Idiopathic intracranial hypertension. Lancet Neurol 2006;5:433-442.

- 2 Friedman DI, Jacobson DM: Diagnostic criteria for idiopathic intracranial hypertension. Neurology 2002;59: 1492-1495.

3 Skau M, Brennum J, Gjerris F, Jensen R: What is new about idiopathic intracranial hypertension? An updated review of mechanism and treatment. Cephalalgia 2006;26:384-399.

4 Higgins JNP, Owler BK, Cousins C, Pickard JD: Venous sinus stenting for refractory benign intracranial hypertension. Lancet 2002;359:228-230.

- 5 Higgins JNP, Cousins C, Owler BK, Sarkies N, Pickard JD: Idiopathic intracranial hypertension: 12 cases treated by venous sinus stenting. J Neurol Neurosurg Psychiatry 2003;74:1662-1666.

- 6 Fields JD, Javedani PP, Falardeau J, et al: Dural venous sinus angioplasty and stenting for the treatment of idiopathic intracranial hypertension. J Neurointerv Surg 2012;5:62-68.

7 Kumpe DAD, Bennett JLJ, Seinfeld JJ, Pelak VSV, Chawla AA, Tierney MM: Dural sinus stent placement for idiopathic intracranial hypertension. J Neurosurg 2012;116:538-548.

- 8 Radvany MG, Solomon D, Nijjar S, et al: Visual and neurological outcomes following endovascular stenting for pseudotumor cerebri associated with transverse sinus stenosis. J Neuroophthalmol 2013;33:117-122.

- 9 Donnet A, Metellus P, Levrier 0, et al: Endovascular treatment of idiopathic intracranial hypertension: clinical and radiologic outcome of 10 consecutive patients. Neurology 2008;70:641-647.

10 He C-ZC, Ji X-MX, Wang L-JL, et al: Endovascular treatment for venous sinus stenosis in idiopathic intracranial hypertension (in Chinese). Zhonghua Yi Xue Za Zhi 2012;92:748-751.

-11 Puffer RC, Mustafa W, Lanzino G: Venous sinus stenting for idiopathic intracranial hypertension: a review of the literature. J Neurointerv Surg 2013;5:483-486.

12 Ahmed RM, Wilkinson M, Parker GD, et al: Transverse sinus stenting for idiopathic intracranial hypertension: a review of 52 patients and of model predictions. Am J Neuroradiol 2011;32:1408-1414.

$\checkmark 13$ Albuquerque FC, Dashti SR, Hu YC, et al: Intracranial venous sinus stenting for benign intracranial hypertension: clinical indications, technique, and preliminary results. World Neurosurg 2011;75:648-652; discussion 592-595.

14 Bussière MM, Falero RR, Nicolle DD, Proulx AA, Patel VV, Pelz DD: Unilateral transverse sinus stenting of patients with idiopathic intracranial hypertension. AJNR Am J Neuroradiol 2010;31:645-650.

15 Ogungbo B, Roy D, Gholkar A, Mendelow AD: Endovascular stenting of the transverse sinus in a patient presenting with benign intracranial hypertension. Br J Neurosurg 2003;17:565-568.

-16 Rajpal S, Niemann DB, Turk AS: Transverse venous sinus stent placement as treatment for benign intracranial hypertension in a young male: case report and review of the literature. J Neurosurg 2005;102(3 suppl):342346.

17 Paquet C, Poupardin M, Boissonnot M, Neau JP, Drouineau J: Efficacy of unilateral stenting in idiopathic intracranial hypertension with bilateral venous sinus stenosis: a case report. Eur Neurol 2008;60:47-48.

18 Owler BK, Parker G, Halmagyi GM, et al: Pseudotumor cerebri syndrome: venous sinus obstruction and its treatment with stent placement. J Neurosurg 2003;98:1045-1055.

19 Lazzaro MA, Darkhabani Z, Remler BF, et al: Venous sinus pulsatility and the potential role of dural incompetence in idiopathic intracranial hypertension. Neurosurgery 2012;71:877-884.

20 Arac A, Lee M, Steinberg GK, Marcellus M, Marks MP: Efficacy of endovascular stenting in dural venous sinus stenosis for the treatment of idiopathic intracranial hypertension. Neurosurg Focus 2009;27:E14.

21 Khalia J, Lynch JR, Fitzsimmons B-F, Remler BF, Zaidat OO: Manometery Guided endovascular management of dural sinus stenosis via balloon angioplasty and stenting (abstract). Proc Am Acad Neurol 62nd Annu Meet, Toronto, 2010, pp 1-67.

22 Zheng H, Zhou M, Zhao B, Zhou D, He L: Pseudotumor cerebri syndrome and giant arachnoid granulation: treatment with venous sinus stenting. J Vasc Interv Radiol 2010;21:927-929.

-23 Teleb MS, Rekate H, Chung S, Albuquerque FC: Pseudotumor cerebri presenting with ataxia and hyper-reflexia in a non-obese woman treated with sinus stenting. J Neurointerv Surg 2012;4:e22.

-24 Farb RI, Vanek I, Scott JN, et al: Idiopathic intracranial hypertension: the prevalence and morphology of sinovenous stenosis. Neurology 2003;60:1418-1424.

-25 Giuseffi V, Wall M, Siegel PZ, Rojas PB: Symptoms and disease associations in idiopathic intracranial hypertension (pseudotumor cerebri): a case-control study. Neurology 1991;41(2, pt 1):239-244.

26 King JO, Mitchell PJ, Thomson KR, Tress BM: Cerebral venography and manometry in idiopathic intracranial hypertension. Neurology 1995;45:2224-2228.

27 Ahmed R, Friedman DI, Halmagyi GM: Stenting of the transverse sinuses in idiopathic intracranial hypertension. J Neuroophthalmol 2011;31:374-380. 
Teleb et al.: Idiopathic Intracranial Hypertension: A Systematic Analysis of Transverse Sinus Stenting

28 Mathew NT, Ravishankar K, Sanin LC: Coexistence of migraine and idiopathic intracranial hypertension without papilledema. Neurology 1996;46:1226-1226.

29 Ramadan NM: Intracranial hypertension and migraine. Cephalalgia 2011;13:210-211.

-30 Huff AL, Hupp SL, Rothrock JF: Chronic daily headache with migrainous features due to papilledema-negative idiopathic intracranial hypertension. Cephalalgia 1996;16:451-452.

-31 Bono F, Messina D, Giliberto C, et al: Bilateral transverse sinus stenosis and idiopathic intracranial hypertension without papilledema in chronic tension-type headache. J Neurol 2008;255:807-812.

32 Bono F, Messina D, Giliberto C, et al: Bilateral transverse sinus stenosis predicts IIH without papilledema in patients with migraine. Neurology 2006;67:419-423.

33 Ekizoglu E, Baykan B, Orhan EK, Ertas M: The analysis of allodynia in patients with idiopathic intracranial hypertension. Cephalalgia 2012;32:1049-1058.

34 Jacobson HG, Shapiro JH: Pseudotumor Cerebri. Radiology 1964;82:202-210.

-35 Durcan FJ, Corbett JJ, Wall M: The incidence of pseudotumor cerebri. Population studies in Iowa and Louisiana. Arch Neurol 1988;45:875-877.

36 Higgins JNP, Gillard JH, Owler BK, Harkness K, Pickard JD: MR venography in idiopathic intracranial hypertension: unappreciated and misunderstood. J Neurol Neurosurg Psychiatry 2004;75:621-625.

37 Johnston I, Kollar C, Dunkley S, Assaad N, Parker G: Cranial venous outflow obstruction in the pseudotumour syndrome: incidence, nature and relevance. J Clin Neurosci 2002;9:273-278.

-38 Karahalios DG, Rekate HL, Khayata MH, Apostolides PJ: Elevated intracranial venous pressure as a universal mechanism in pseudotumor cerebri of varying etiologies. Neurology 1996;46:198-202.

39 Riggeal BD, Bruce BB, Saindane AM, et al: Clinical course of idiopathic intracranial hypertension with transverse sinus stenosis. Neurology 2013;80:289-295.

40 Rohr A, Dörner L, Stingele R, Buhl R, Alfke K, Jansen O: Reversibility of venous sinus obstruction in idiopathic intracranial hypertension. AJNR Am J Neuroradiol 2007;28:656-659.

41 Ludyga T, Kazibudzki M, Simka M, et al: Endovascular treatment for chronic cerebrospinal venous insufficiency: is the procedure safe? Phlebology 2010;25:286-295.

42 Ye K, Lu X, Li W, et al: Long-term outcomes of stent placement for symptomatic nonthrombotic iliac vein compression lesions in chronic venous disease. J Vasc Intervent Radiol 2012;23:497-502.

-43 Farb RI, Scott JN, Willinsky RA, Montanera WJ, Wright GA, terBrugge KG: Intracranial venous system: gadolinium-enhanced three-dimensional MR venography with auto-triggered elliptic centric-ordered sequenceinitial experience. Radiology 2003;226:203-209.

-44 McGirt MJ, Woodworth G, Thomas G, Miller N, Williams M, Rigamonti D: Cerebrospinal fluid shunt placement for pseudotumor cerebri-associated intractable headache: predictors of treatment response and an analysis of long-term outcomes. J Neurosurg 2004;101:627-632.

45 Plotnik JL, Kosmorsky GS: Operative complications of optic nerve sheath decompression. Ophthalmology 1993;100:683-690.

-46 Spoor TC, McHenry JG: Long-term effectiveness of optic nerve sheath decompression for pseudotumor cerebri. Arch Ophthalmol 1993;111:632-635.

-47 Spoor TC, McHenry JG, Shin DH: Long-term results using adjunctive mitomycin C in optic nerve sheath decompression for pseudotumor cerebri. Ophthalmology 1995;102:2024-2028.

48 Corbett JJ, Nerad JA, Tse DT, Anderson RL: Results of optic nerve sheath fenestration for pseudotumor cerebri. The lateral orbitotomy approach. Arch Ophthalmol 1988;106:1391-1397.

49 ClinicalTrials.gov: Venous sinus stenting for idiopathic intracranial hypertension refractory to medical therapy (VSSIIH). Bethesda, National Library of Medicine. http://clinicaltrials.gov/ct2/show/NCT01407809 (accessed October 7, 2013). 